\title{
EFEKTIVITAS BERBAGAI FUNGI MIKORIZA ARBUSKULAR INDIGENUS TERHADAP SERAPAN HARA P DAN PERTUMBUHAN TANAMAN JARAK PAGAR (Jatropha curcas L.)
}

\author{
Muzakkir, Eti Farda Husin, Agustian, dan Auzar Syarif \\ Pascasarja Universitas Andalas
}

\begin{abstract}
Utilization of arbuscular mycorrhizae fungi (FMA) is an alternative way to improve soil fertility. Therefore, it must be developed by studying deeply the effectivity of the FMA. This is important due to either its ability to associate with almost all of vegetation family in terrestrial ecosystems or its ability to increase plant growth rate, seedlings quality, and crop yield, especially on critical land. A research about effectivity of variously indigenous arbuscular mycorrhizae fungi on P-sorption and Jatropha growth was conducted at laboratorium and glasshouse Agriculture Faculty, Andalas University. This research was aimed to gain the most effective isolate of arbuscular mycorrhizae fungi on growth of and P-sorption by Jatropha (Jatropha curcas L.) plant on critical land. Single isolat such as Glomus $\mathrm{sp}_{2}$, Acaulospora $\mathrm{sp}_{1}$, Gigaspora $\mathrm{sp}_{1}$, and compound isolate M7 (Glomus $\mathrm{sp}_{2},+$ Acaulospora $\mathrm{sp}_{1}+$ Gigaspora $\mathrm{sp}_{1}$ ) significantly affected plant height, canopy dry matter, infection percentage and intensity, and Psorption. M7 Compound isolate was the most effective innoculum. By this isolate, height of Jatropha seedlings was $27.5 \mathrm{~cm}$, canopy dry matter $5.9 \mathrm{~g}$, infection percentage $78.5 \%$, infection intensity was 49.1, and P-sorption by canopy was $1.6 \mathrm{~g}$ for each seedling.
\end{abstract}

Keywords: Effectiveness of FMA

\section{PENDAHULUAN}

Kerusakan lahan bertambah terus seiring dengan meningkatnya jumlah penduduk yang berakhir dengan bertambah luasnya lahan kritis. Data tahun 1992 menunjukkan bahwa luas lahan kritis di Indonesia diluar kawasan hutan telah mencapai \pm 18 juta hektar, sedangkan tahun 2005 telah mencapai \pm 25 juta hektar (Direktorat Jenderal Pengelolaan Lahan dan Air Departemen Pertanian, 2007). Di Sumatera Barat luas lahan kritis mencapai 267 ribu hektar. Dari luasan tersebut 20 ribu hektar terhampar disekitar danau Singkarak (Tim Faperta Unand, 1992). Pada lahan kritis yang luas ini terdapat Cendawan Mikoriza Indigenus yang berpotensi dapat ditingkatkan efektifitasnya dan diproduksi dalam berbagai bentuk inokulan sehingga dapat digunakan sebagai pupuk hayati (biofertilizer) yang tidak saja murah dan efektif tetapi juga bersifat ramah dengan lingkungan.

Infeksi FMA akan lebih efektif, apabila mengembalikan jenis-jenis FMA indigenus (Setiadi, 1998). Efektivitas FMA bergantung pada kompatibilitas antara jamur dan tanaman. Karena itu variasi genetik tanaman maupun jamur mempengaruhi efektivitas simbiosis (Heijden E.W., 2001). Keefektifan FMA dalam simbiosisnya dengan tanaman pada tanah yang bereaksi masam akan dipengaruhi oleh toleransinya terhadap kemasaman tanah, kejenuhan $\mathrm{Al}$ tinggi, dan ketersediaan hara yang rendah. Hasil penelitian Bartolome-Esteben dan Schenck (1994) menunjukkan bahwa sebagian besar spesies dalam genus Gigaspora menunjukkan toleransi yang besar terhadap Al. Sedangkan spesies dalam genus Glomus pada umumnya tidak toleran terhadap kejenuhan Al tinggi kecuali Glomus manihotis yang perkecambahan sporanya stabil pada keadaan kejenuhan Al.

Perbedaan infektivitas dapat terjadi diantara berbagai jenis FMA, yang dapat disebabkan oleh perbedaan pertumbuhan hifa pada akar. Kemampuan pertumbuhan dan penyebaran hifanya sangat bervariasi tergantung jenis FMA itu sendiri maupun inangnya, yang dapat terjadi dengan laju pertumbuhan 0,4 mm/hari sampai 2,5 mm per hari (Wilson dan Tommerup, 1992). 

Secara alami sistem perakaran tanaman jarak pagar ditemukan infeksi FMA pada jaringan korteknya tetapi tingkat asosiasinya perlu dilakukan penelitian. Walaupun FMA mampu berasosiasi dengan berbagai jenis tanaman, tetapi belum diketahui dan belum ditemukan genus FMA mana yang paling efektif dalam neningkatkan pertumbuhan tanaman jarak pagar.

Berkaitan dengan masalah diatas perlu dilakukan penelitian mengenai Efektivitas Berbagai Genus Fungi Mikoriza Arbuskula Indigenus terhadap Serapan Hara $\mathrm{P}$ dan Pertumbuhan Tanaman Jarak Pagar(Jatropha curcas L.) di Lahan Kritis. Penelitian ini bertujuan untuk Mendapatkan isolat Fungi Mikoriza Arbuskula indigenus yang paling efektif terhadap serapan hara $\mathrm{P}$ pada tanaman jarak pagar (Jatropha curcas L.) di lahan kritis. Manfaat dari penelitian ini adalah memberikan informasi tentang Efektivitas berbagai jenis FMA indigenous dalam meningkatkan pertumbuhan bibit tanaman jarak pagar (Jatropha curcas L.) di lahan kritis

\section{BAHAN DAN METODA}

\subsection{Tempat dan Waktu}

Perbanyakan mikoriza dilakukan di rumah kaca Fakultas Pertanian Universitas Andalas. Analisis mikoriza dilakukan di Laboratoum Mikrobiologi Jurusan Ilmu Tanah dan Hama Penyakit, sedangkan analisis tanah dan jaringan tanaman dilakukan pada Laboratorium P3IN Unand. Percobaan ini akan dilakukan di Rumah kawat Fakultas Pertanian Unand selama 4 bulan (Agustus 2008 - Nopember 2008).

\subsection{Metodologi Penelitian}

Penelitian merupakan percobaan 1 faktor dengan menggunakan rancangan acak lengkap (RAL). Setiap perlakuan diulang 3 kali sehingga diperoleh $6 \times 1 \times 3=18$ satuan percobaan. Pengamatan dalam penelitian ini dilakukan terhadap peubah: persentasi infeksi, dan Intensitas infeksi akar, bobot kering tajuk (g), dan kadar P jaringan tanaman. Data penelitian hasil pengamatan diuji dengan analisis ragam dan jika perlakuan penunjukkan pengaruh yang nyata, maka dilanjutkan dengan BNT taraf kepercayaan 95\%. (Steel and Tory, 1980)

Percobaan ini terdiri dari beberapa perlakuan yaitu :

Mo :tanpa inokulasi FMA

$\mathbf{M}_{1}$ : Inokulum FMA indigenus (Glomus $\mathrm{sp}_{2}$ )

$\mathbf{M}_{2}$ :Inokulum FMA indigenus (Acaulospora $\mathrm{sp}_{1}$ )

$\mathbf{M}_{3}$ :Inokulum FMA indigenus (Gigaspora $\left.\mathrm{sp}_{1}\right)$

$\mathbf{M}_{\mathbf{4}}$ :Inokulum FMA indigenus (Glomus $\mathrm{sp}_{2}+$ Acaulospora $\mathrm{sp}_{1}$ )

$\mathbf{M}_{5}$ :Inokulum FMA indigenus (Glomus $\mathrm{sp}_{2}$ + Gigaspora $\mathrm{sp}_{1}$ ))

$\mathbf{M}_{6}$ :Inokulum $\quad$ FMA indigenus (Acaulospora $\mathrm{sp}_{1}+$ Gigaspora $\mathrm{sp}_{1}$ )

$\mathbf{M}_{7}$ :Inokulum FMA indigenus (Glomus $\mathrm{sp}_{2}$ + Acaulospora $\mathrm{sp}_{1}+$ Gigaspora $\mathrm{sp}_{1}$ )

\section{HASIL DAN PEMBAHASAN}

\section{A. Tinggi Tanaman dan Berat Kering Tajuk Bibit Tanaman Jarak Pagar}

Hasil pengamatan secara visual menunjukkan terjadi perbedaan pertumbuhan bibit tanaman jarak pagar akibat pemberian berbagai isolat FMA seperti Gambar 1. Analisis ragam tinggi tanaman dan bobot kering tajuk jarak pagar 58 hari setelah inokulasi FMA menunjukkan bahwa berbagai isolat FMA berpengaruh terhadap tinggi tanaman dan bobot kering tajuk jarak pagar (Tabel 1).

Isolat M4 (Glomus sp2 + Acaulospora sp1) memberikan respon yang lebih tinggi, dan tidak berbeda nyata dengan isolat M5 (Glomus sp2 + Gigaspora sp1) dan isolat M6 (Acaulospora sp1 + Gigaspora sp1), namun berbeda nyata bila dibandingkan dengan isolat M1 (Glomus sp2), isolat M2 (Acaulospora sp1), isolat M3 (Gigaspora sp1) dan tanpa pemberian FMA. Perbedaan respon ini disebabkan oleh adanya perbedaan jumlah jenis FMA, dimana apabila dua jenis FMA yang berasosiasi dengan akar tanaman jarak pagar, 


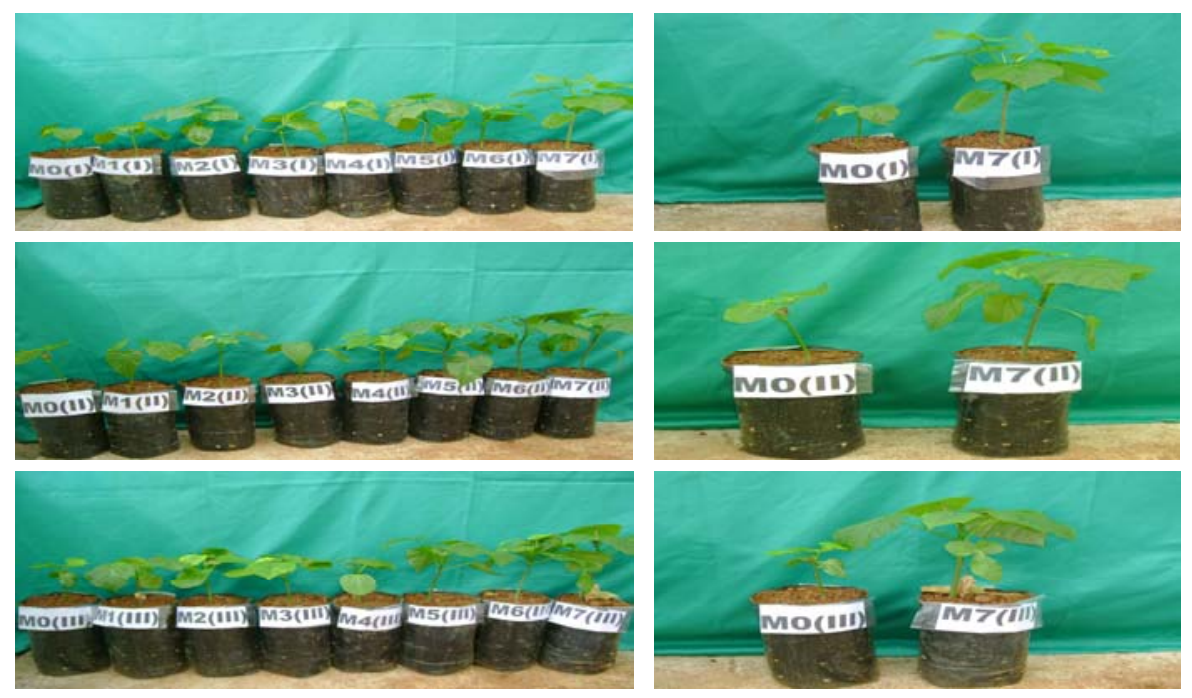

Gambar 1. Penampilan pertumbuhan bibit jarak pagar yang diinokulasi dengan berbagai isolat FMA

kemampuannya lebih tinggi dalam penyerapan hara dan air dibandingkan dengan satu jenis dan tanpa FMA. Crus et al (2000) menyatakan tanaman yang diinokulasi mikoriza akan menyerap hara dan air lebih banyak dari pada tanaman yang tidak diinokulasi mikoriza. Hasil penelitian Douds et al (1990) menyatakan tanaman gandum yang diinfeksi dengan Glomus mossae tumbuh lebih baik dan memberikan bobot kering yang lebih tinggi dibandingkan dengan kontrol.

Inokulasi isolat M7 (Glomus.sp1+ Acaulospora sp1 + Gigaspora sp1) memberikan respon pertumbuhan yang lebih tinggi dan berbeda nyata bila dibandingkan dengan tanpa FMA dan Isolat lainnya. Hal ini disebabkan inokulum campuran dengan spesies yang lebih banyak (tiga jenis FMA) mampu bekerja secara mandiri tanpa ada antagonisme sehingga kemampuannya lebih tinggi dalam penyerapan hara dan air dibanding isolat lainnya yang bekerja berdua dan secara mandiri. Hal ini tergambar dari hasil penelitian dimana persentase dan intensitas infeksi isolat M7 yang lebih tinggi dari isolat lainnya. Sieverding (1991) menyatakan kolonisasi akar tanaman akan tinggi oleh inokulum campuran dengan

Tabel 1. Tinggi tanaman dan berat kering bagian atas tanaman jarak pagar dengan pemberian berbagai isolat FMA

\begin{tabular}{lcc}
\hline \multicolumn{1}{c}{$\begin{array}{c}\text { Perlakuan } \\
\text { (Isolat FMA })\end{array}$} & $\begin{array}{c}\text { Tinggi Tanaman } \\
(\mathrm{cm})\end{array}$ & $\begin{array}{c}\text { Berat Kering Tajuk } \\
(\mathrm{g} / \mathrm{bibit})\end{array}$ \\
\hline Glo.sp ${ }_{1}+$ Aca $\mathrm{sp}_{1}+$ Gigaspora $\mathrm{sp}_{1}\left(\mathrm{M}_{7}\right)$ & $27.53 \mathrm{a}$ & $5.92 \mathrm{a}$ \\
Glomus $\mathrm{sp}_{2}+$ Acaulospora $\mathrm{sp}_{1}\left(\mathrm{M}_{4}\right)$ & $23.26 \mathrm{~b}$ & $4.93 \mathrm{~b}$ \\
Glomus $\mathrm{sp}_{2}+$ Gigaspora $\mathrm{sp}_{1}\left(\mathrm{M}_{5}\right)$ & $23.06 \mathrm{~b}$ & $4.62 \mathrm{bc}$ \\
Acaulospora $\mathrm{sp}_{1}+$ Gigaspora $\mathrm{sp}_{1}\left(\mathrm{M}_{6}\right)$ & $21.86 \mathrm{bc}$ & $4.44 \mathrm{c}$ \\
Glomus $\mathrm{sp}_{2}\left(\mathrm{M}_{1}\right)$ & $20.63 \mathrm{~cd}$ & $3.72 \mathrm{~d}$ \\
Acaulospora $\mathrm{sp}_{1}\left(\mathrm{M}_{2}\right)$ & $19.73 \mathrm{~cd}$ & $3.54 \mathrm{~d}$ \\
Gigaspora $\mathrm{sp}_{1}\left(\mathrm{M}_{3}\right)$ & $18.2 \mathrm{~d}$ & $3.41 \mathrm{~d}$ \\
Tanpa CMA $\left(\mathrm{M}_{0}\right)$ & $14.5 \mathrm{e}$ & $1.75 \mathrm{e}$ \\
\hline
\end{tabular}

Angka-angka pada kolom yang sama dan diikuti oleh huruf kecil yang sama berbeda tidak nyata menurut DNMRT pada taraf 5\%. 

spesies FMA yang lebih banyak, juga pertumbuhan dan bobot kering tanaman lebih tinggi dibandingkan dengan tanaman yang dikelonisasi oleh inokulum FMA campuran tetapi keragaman spesiesnya lebih sedikit. Respon yang berlainan terhadap tinggi tanaman dan bobot kering tanaman akibat inokulasi beberapa isolat FMA terlihat jeruk (Camprubi dan Calvet, 1996).

\section{B. Persentasi dan Intensitas Infeksi Akar}

Penilaian persentase dan intensitas infeksi dilakukan melalui pengamatan secara mikroskopis mengenai keberadaan hifa, vesikel, dan arbuskul baik di dalam dan diluar sel kortek akar. Secara umum tipe infeksi FMA pada akar tanaman jarak pagar terdiri dari tipe arum (Glomus sp) dan tipe paris (Acaulospora dan Gigaspora sp) seperti Gambar 2.
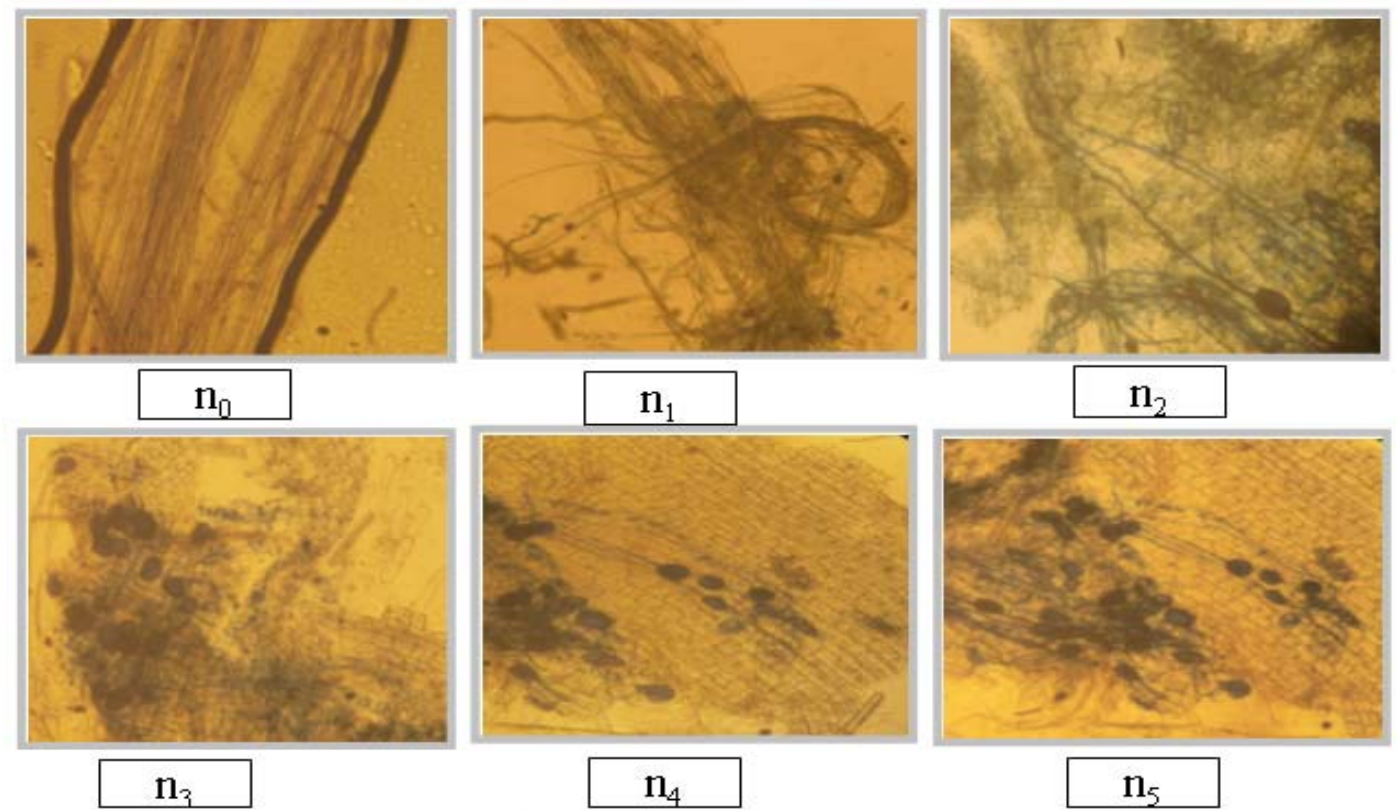

$\mathbf{n}_{3}$

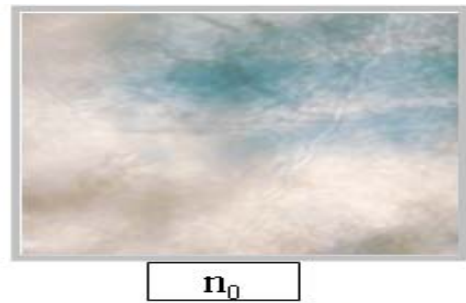

Tipe Paris
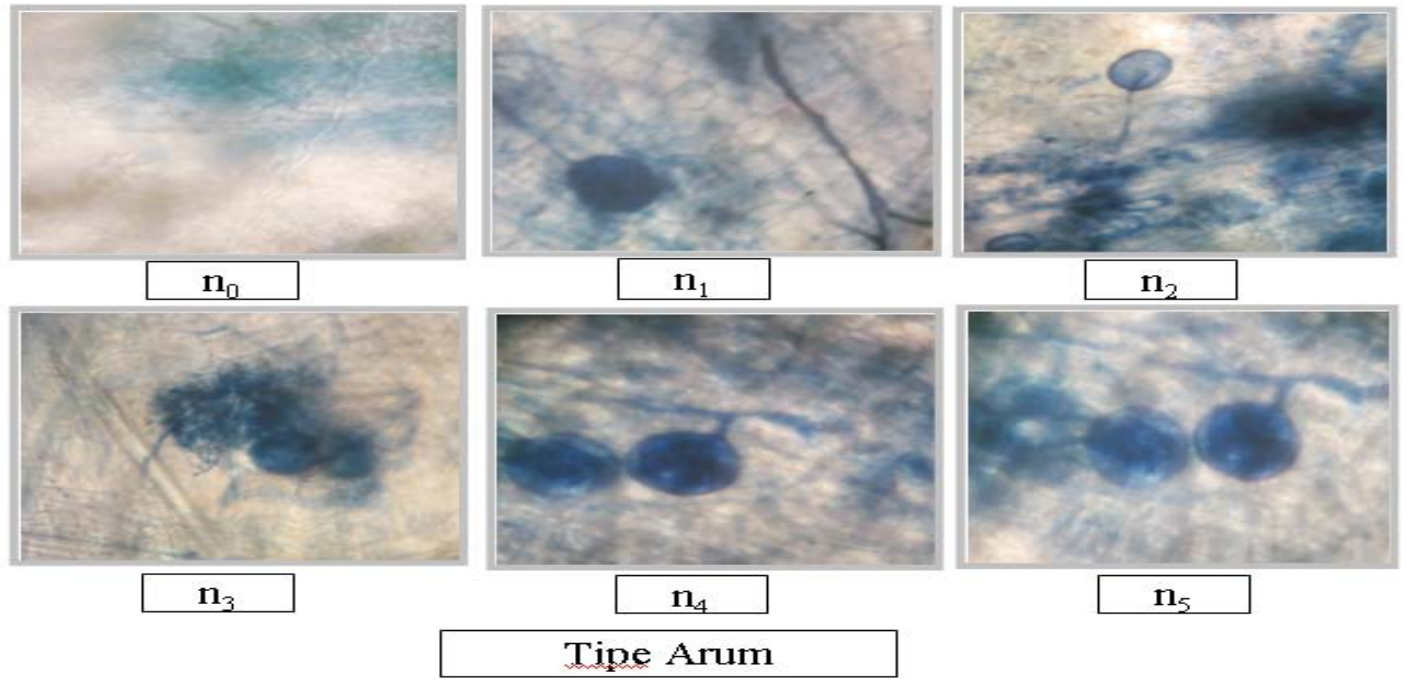

Gambar 2. Tipe infeksi FMA pada akar Tanaman Jarak Pagar 
Tabel 2. Persentase infeksi dan intensitas infeksi berbagai isolate CMA terhadap tanaman jarak pagar

\begin{tabular}{lcc}
\hline \multicolumn{1}{c}{ Perlakuan (Isolat FMA) } & Persen infeksi & Intensitas infeksi \\
\hline Glo.sp1+ Aca sp1 + Gigaspora sp1 (M7) & $78.50 \mathrm{a}$ & $49.10 \mathrm{a}$ \\
Glomus sp2 + Acaulospora sp1 (M4) & $49.29 \mathrm{~b}$ & $34.28 \mathrm{~b}$ \\
Glomus sp2 + Gigaspora sp1 (M5) & $49.89 \mathrm{~b}$ & $32.81 \mathrm{~b}$ \\
Acaulospora sp1 + Gigaspora sp1 (M6) & $48.51 \mathrm{~b}$ & $32.48 \mathrm{~b}$ \\
Glomus sp2 (M1) & $45.92 \mathrm{~b}$ & $27.01 \mathrm{c}$ \\
Acaulospora sp1 (M2) & 40.16 c & 25.71 c \\
Gigaspora sp1 (M3) & 39.14 c & 23.51 c \\
Tanpa CMA (M0) & 11.03 d & $2.53 \quad$ d \\
\hline Angka
\end{tabular}

Angka-angka pada kolom yang sama dan diikuti oleh huruf kecil yang sama berbeda tidak nyata menurut DNMRT pada taraf 5\%.

Dua bulan (58 hari) setelah inokulasi berbagai isolat FMA secara statistik menunjukkan adanya pengaruh serta perbedaan persen infeksi dan intensitas infeksi terhadap bibit tanaman jarak pagar (Tabel 2).

Tingkat infeksi akar, tanpa FMA berbeda nyata dengan pemberian berbagai isolat FMA, juga isolat spora tunggal (M1, M2, M3) berbeda nyata dengan isolate campuran (M4, M5, M6). Persen infeksi dan intensitas infeksi tertinggi diperoleh pada inokulum campuran yaitu pada isolate M7 (Glomus.sp1+ Acaulospora sp1 + Gigaspora sp1) dan berbeda nyata dengan berbagai isolat FMA lainnya. . Hal ini menunjukkan bahwa tingkat kolonisasi yang terbentuk pada akar tanaman jarak pagar bervariasi antara spesies berbagai isolate FMA. Fenomena tingkat infeksi yang rendah dan yang tinggi sangat ditentukan oleh kesesuain FMA dengan tanaman (Brundrett and N. Malajczuk. 1996), faktor lingkungan, serta senyawa kimia yang dihasilkan tanaman (Anderson, 1992). Apabila dihubungkan dengan penggolongan intensitas infeksi akar berdasarkan Trouvelot, Kough dan Gianinazzi-Pearson, (1986) tergolong sedang, dimana isolat M7 (Glomus.sp1+ Acaulospora sp1 + Gigaspora sp1) termasuk kelas 4 (51-90 \% terinfeksi), sementara isolat lain termasuk kelas 3 (11-50 \% terinfeksi). Berdasarkan persen infeksi dan intensitas infeksi, isolat M7 (Glomus.sp1+ Acaulospora sp1 + Gigaspora sp1) dapat diaplikasikan pada tanaman jarak pagar, namun demikian perlu dilihat kefektifannya terhadap serapan hara P.

\section{B. Serapan $\mathbf{P}$}

Inokulasi berbagai isolat FMA memberikan efek yang lebih tinggi dan berbeda nyata jika dibandingkan dengan tanpa FMA (kontrol). Isolat M7 (Glomus.sp1+ Acaulospora sp1 + Gigaspora sp1) memberikan serapan hara $\mathrm{P}$ serta bobot kering tertinggi dan berbeda nyata, jika dibandingkan dengan isolat FMA yang lain (Tabel 3).

Keadaan ini dapat terjadi karena perbedaan keefektifan dari isolate tersebut di atas dalam hal meningkatkan absorbsi hara. Sieverding (1991) mengemukakan bahwa tingkat infeksi FMA yang tinggi pada suatu tanaman, tidak selalu diiringi dengan keefektifan yang tinggi dalam absorpsi hara. Perbedaan kefektifan beberapa jenis isolate FMA dalam meningkatkan penyerapan hara, antara lain dipengaruhi oleh kemampuannya meningkatkan penyebaran hifa yang sempurna dalam tanah, kemampuan dalam membentuk kolonisasi yang luas, efisiensi absorpsi hara terutama fosfor dalam tanah, dan waktu yang dibutuhkan dalam transfortasi hara melalui hifa menuju tanaman (Bagyaraj, 1992).

Kemampuan berbagai isolate FMA berbeda-beda dalam meningkatkan penyerapan $\mathrm{P}$ dan pertumbuhan tanaman jarak pagar pada lahan kritis. Hal ini 
disebabkan oleh adanya perbedaan intensitas infeksi yang tergambar dari

Tabel 3. Serapan P tanaman jarak pagar dengan pemberian berbagai isolat FMA

\begin{tabular}{lc}
\multicolumn{1}{c}{ Perlakuan (Isolat FMA) } & Serapan P (g/bibit) \\
\hline Glo.sp1+ Aca sp1 + Gigaspora sp1 (M7) & $1.61 \mathrm{a}$ \\
Glomus sp2 + Acaulospora sp1 (M4) & $1.23 \mathrm{~b}$ \\
Glomus sp2 + Gigaspora sp1 (M5) & $1.11 \mathrm{c}$ \\
Acaulospora sp1 + Gigaspora sp1 (M6) & $1.10 \mathrm{c}$ \\
Gigaspora sp1 (M3) & $0.8 \mathrm{~d}$ \\
Glomus sp2 (M1) & $0.78 \mathrm{~d}$ \\
Acaulospora sp1 (M2) & $0.75 \mathrm{~d}$ \\
Tanpa CMA (Mo) & $0.12 \mathrm{e}$
\end{tabular}

Angka-angka pada kolom yang sama dan diikuti oleh huruf kecil yang sama berbeda tidak nyata menurut DNMRT pada taraf 5\%.

adanya perbedaan hifa, vesikel dan arbuskula di dalam dan diluar sel kortek akar.).Banyaknya hifa eksternal pada zona perakaran akan meningkatkan volume tanah yang dapat dieksploitasi untuk penyerapan pospor.

Peningkatan penyerapan $\mathrm{P}$ oleh tanaman yang terinfeksi FMA diduga karena adanya peningkatan aktivitas enzim phosphatase pada rhizosfir pada akar tanaman Douds et al (1990) telah membuktikan bahwa aktivitas enzim pada akar dan rhizosfir tanaman gamdum yang terinfeksi FMA (Glomus mossae dan Glomus geosporium) lebih tinggi dibading dengan kontrol dan secara nyata meningkatkan pertumbuhan (berat kering) dan kandungan $\mathrm{P}$ tanaman. Aktivitas enzim phosphatase telah diketahui secara positif berkorelasi dengan penyerapan $\mathrm{P}$ dan pertumbuhan tanaman pada tanah yang kekurangan fosfor. Hal ini sesuai dengan hasil yang diperoleh dalam penelitian ini, bahwa inokulasi berbagai spesies CMA dapat meningkatkan serapan $\mathrm{P}$ tanaman, namun efek dari beberapa jenis isolat yang diinokulasikan tidak sama, dimana serapan $\mathrm{P}$ tertinggi diperoleh pada isolat M7 (Glomus.sp1+ Acaulospora sp1 + Gigaspora sp1) yaitu 1.61 gram/ bibit. Hal ini memberikan gambaran bahwa pemberian tiga jenis FMA( isolat M7) secara bersamaan sesuai dengan tanaman inang akan memberikan respon yang lebih tinggi terhadap serapan hara $\mathrm{P}$ dibanding dengan pemberian satu, dan dua jenis isolat FMA serta tanpa FMA. Dengan demikian isolat M7 campuran (Glomus.sp1+ Acaulospora sp1 + Gigaspora sp1) perlu diberikan bahan pembawa terbaik, kemudian diuji efektivitasnya di lapangan atau di lahan keritis Tanjung alai Solok sumatera Barat.

\section{KESIMPULAN DAN SARAN}

\section{Kesimpulan}

1. Isolat tunggal $\mathrm{M}_{1}$ (Glomus $\left.\mathrm{sp}_{2}\right), \mathrm{M}_{2}$ (Acaulospora $\mathrm{sp}_{1}$ ), $\mathrm{M}_{3}$ (Gigaspora $\mathrm{sp}_{1}$ ), dan isolat campuran (Glomus $\mathrm{sp}_{2},+$ Acaulospora $\mathrm{sp}_{1}+$ Gigaspora $\mathrm{sp}_{1}$ ) secara nyata berpengaruh terhadap tinggi tanaman ,bobot kering tajuk, persen infeksi , intensitas infeksi , dan serapan hara $\mathrm{P}$.

2. Isolat $\mathrm{M}_{7}$ campuran (Glomus $\mathrm{sp}_{2}+$ Acaulospora $\mathrm{sp}_{1}+$ Gigaspora $\mathrm{sp}_{1}$ ) merupakan inokulum yang paling efektif, dimana pada umur 58 hari memberikan tinggi bibit jarak pagar $27,53 \mathrm{~cm}$, bobot kering tajuk 5,92 g/bibit, persen infeksi 78,50, intensitas infeksi 49,10 dan serapan P tajuk 1.61 g/bibit

\section{Saran}

Perlu penelitian lebih lanjut mengenai formulasi bahan pembawa untuk mendapatkan bahan pembawa terbaik dari 
isolat $\mathrm{M}_{7}$ (Glomus $\mathrm{sp}_{2}+$ Acaulospora $\mathrm{sp}_{1}+$ Gigaspora $\left.\mathrm{sp}_{1}\right)$.

\section{DAFTAR PUSTAKA}

Anderson J.M., and Ingram J.S.I., 1992. Tropical soil biology and fertility. A Handbook of Methods. Second Edition. Rathmamsted International Rathamsted Experimental Station. Herpenden, ALS 2JQ. CAB International. 221: (172-183).

Bagyaraj, D. J. 1992., Vesicular-arbuscular mycorrhizal : application in agriculture. In J. R. Norris, D. J. Read and A.K. Varma (Eds.), Techniques for Mycorrhizal Research 3, pp. 819 833. Academic Press, London.

Brundrett,. M, Bougher., N. Dell, B. Grove, and N. Malajczuk. 1996. Working With Mycorrhizas in Forestry and Agriculture. ACIAR. Canberra

Camprubi, A., and C. Calvet, 1996. Isolation and screening of mycorrhizal fungi from citrus nurseries and orchards and inoculation studies. Hort Science 31:366-369.

Cruz, C, JJ Green, CA Watson, F Wilson, dan MA Martin-Loucao., 2000. Functional aspects of root architecture and mycorrhizal inoculation witth respect ton nutrient uptake capacity. Mycorrhiza. 14; 177-184.

De La Cruz, D.E. 1988. General lectures on mycorrhiza. Workshop on Mycorrhiza Inoc. Comp UIP the Philippines.
Douds, D.D., Jr, and N.C. Schenck., 1990. Cryopreservation of spores of vesicular-arbuscular mycorrhizal fungi. New Phytol. 115: 667-674.

Heijden E.W. van der., 2001. Differential benefits of arbuscular mycorrhizal and ectomycorrhizal infection of Salix repens. Mycorrhiza 10:185-193.

Setiadi,Y. 1996. Working with arbuscularmycorrhizal fungi for tropical condtions. Inter University Report. Unpublished

Smith SE, Read DJ. 1997. Mycorrhizal Symbiosis. Second Edition. London: Academic Press Hacourt Brace \& Company Publisher. 32-79

Sieverding E. 1991. Vesicular-Arbuscular Mycorrhiza Management in tropical agrosystems. Deutsche Gesellschaft fur. Technische Zusammenarbeit (GTZ) Gmb. Federal Republic of Germany. 371 p.

Trouvelot, A.J., L Kough et V. GianinazziPerson., 1986. Measure du Taux de mycorrization vesicle arbuscular d,un systeme radiaculaire. Recherche de Methodes d,Estimation Ayant Une Signification Fonctionnelle. INRA. Station d Amelioration des Plantes. Laboratoire de Phytoporasitologi. BV 1540.21034 Dijon Cedex France. 